\title{
EVALUATION OF TENSILE STRENGTH OF GLASS FROM COMBINED EXPERIMENTAL AND NUMERICAL ANALYSIS OF LAMINATED GLASS
}

\author{
ALENA ZEMANOVÁ, JAROSLAV SCHMIDT \& MICHAL ŠEJNOHA \\ Department of Mechanics, Czech Technical University in Prague, Czech Republic
}

\begin{abstract}
This paper is concerned with the evaluation of tensile strength of annealed and heat-strengthened glass from a given set of samples. The values of tensile stresses at failure corresponding to the strengths of samples are determined from experimentally measured strains and also computed numerically using the known value of the critical load and loading scenario only. In contrast to common testing procedures performed on monolithic glass samples, laminated glass specimens are analyzed in our study to account for a potential impact of the process of fabrication. The data sets from two types of experiments are examined. In particular, the measured response from four-point bending tests is complemented with that for simply-supported laminated glass samples loaded in bending by a uniformly distributed pressure. The experimentally measured data are compared with those derived numerically to support the proposed computational model. In this regard, the results of small scale testing needed in calibrating the constitutive model of the polymer interlayer are also discussed in connection to ethylen-vinyl acetate and polyvinyl butyral foils.

Keywords: annealed glass, heat-strengthened glass, laminated glass, tensile strength in bending, ethylen-vinyl acetate, polyvinyl butyral, rheometer.
\end{abstract}

\section{INTRODUCTION}

The knowledge of strength of glass is essential for the design of transparent structures made of monolithic or laminated glass. The strength is often a determinative parameter in models analyzing the failure and fracture of glass. Whilst the resistance of glass to compressive stress is high, its resistance to tensile stress is significantly lower due to commonly encountered surface flaws. This is also the cause of a relatively high scatter in the tensile strength measured experimentally on large structural specimens. From a different prospective it makes the tensile strength a decisive parameter governing the bearing capacity of most of the glass structures, which are typically plates in bending.

Two common testing procedures to obtain glass strength data are the four-point bending or coaxial double ring tests on specimens made of a monolithic glass [1]. Then, the tensile strength of a sample is determined from the tension stresses at failure. Because the strength of glass strongly depends on many aspects, e.g., the condition of surface, the size of the glass element, the loading history, the residual stresses, or the environmental conditions, the test results are statistically analyzed and evaluated; generally by fitting to a two-parameter Weibull distribution [2].

However, in most practical applications the glass structures typically appear in the form of laminates. Modeling of such structural units is considerably more demanding in comparison to the modeling of monolithic glass. Validating the numerical simulations thus calls for performing measurements on the same type of structures. Apart from determining the desired tensile strength such types of experiments open the way to assessing the load bearing capacity of actual structural units and thus accounting for the actual manufacturing process. This strategy is therefore adopted in the present study aiming at appraising the tensile strength of glass from a combined experimental and numerical analysis of laminated glass 
samples. Attention is limited to three-layer laminates made of two panes of annealed or heatstrengthened glass bonded two either ethylen-vinyl acetate (EVA) or polyvinyl butyral (PVB) interlayer foils.

To describe this research effort we organize the paper into the remaining five sections. Prior to discussing the principal goal we briefly summarize in Section 2 the calibration of the constitutive model of the two interlayers as they play an important role in a reliable prediction of the laminated glass response. Section 3 then describes the experimental program providing the data from both the classical four-point bending tests and measurements performed on simply-supported samples loaded in bending by uniformly distributed pressure. This experimental study is complemented with numerical analysis described next in Section 4. Therein, the tensile stresses at failure are computed from known values of the critical load. Such numerical or analytical calculations are, besides the strain measurements with strain gauges, one of the approaches used for the estimation of tensile stresses on monolithic glass plates [1]. However, this analysis is not so common for laminated glass samples because the unknown mechanical properties of interlayers make the determination of stress distribution in glass plies impossible, thus further justifying our research effort when addressing this issue. Finally, the strength of the whole set is statistically evaluated, and the main findings are summarized in the concluding Section 6.

\section{DYNAMIC TORSION TESTS ON POLYMER FOILS}

As mention in the introductory part, this section addresses the behavior of two polymer foils made of ethylen-vinyl acetate (EVA) and polyvinyl butyral (PVB). It has been shown that the time and temperature dependent response of this material can be well described by the viscoelastic generalized Maxwell chain model plotted in Fig. 1, see e.g. [3]. This suggests the shear modulus at a given time instant $t$ be written in the form

$$
G(t)=G_{\infty}+\sum_{i=1}^{n} G_{i} e^{-G_{i} t / \eta_{i}}=f\left(G_{\infty},\left\{G_{i}\right\}_{i=1, \ldots, n}\right) .
$$

Assuming the relaxation times $\tau_{i}=\frac{G_{i}}{\eta_{i}}$ are known leaves us with the shear moduli $G_{\infty}$ and $\left\{G_{i}\right\}_{i=1, \ldots, n}$ of the chain units to be calibrated. In the light of the adopted dynamic torsion experiments it becomes useful to rewrite eqn (1) in terms of the complex modulus $G^{*}$ as

$$
G^{*}(\omega, T)=G_{\infty}+\sum_{i=1}^{n} G_{i} \frac{a_{T}(T) \omega^{2} \tau_{i}^{2}}{a_{T}(T) \omega^{2} \tau_{i}^{2}+1}+\sum_{i=1}^{n} G_{i} \frac{a_{T}(T) \omega \tau_{i}}{a_{T}(T) \omega^{2} \tau_{i}^{2}+1}
$$

where $\omega$ is the harmonic frequency and $a_{T}(T)$ is the temperature shift factor shifting the experimental results obtained at a certain temperature $T$ to those corresponding to a chosen reference temperature $T_{R}$. In this study, the parameter $a_{T}(T)$ is evaluated from the WilliamsLandel-Ferry (WLF) equation

$$
\log a_{T}(T)=\frac{-C_{1}\left(T-T_{R}\right)}{C_{2}+T-T_{R}}
$$

where $C_{1}, C_{2}$ are additional model parameters to be determined. The data entering the accompanying calibration procedure are provided in this study from the dynamic shear rheometer test as originally proposed in [3].

Herein, the measurements were carried out using the HAAKE MARS apparatus. To that end, cylindrical samples drilled out from laminated glass plates were glued between two 


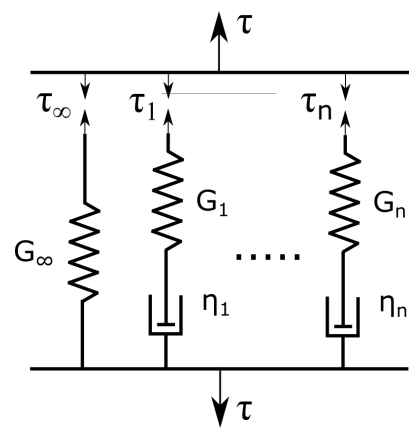

Figure 1: Generalized Maxwell model with $n$ Maxwell cells.
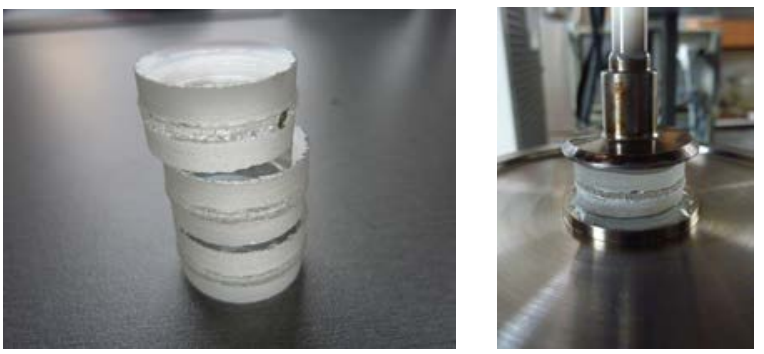

Figure 2: Drilled out samples and one sample glued to rheometer device.

plates where the bottom plate is fixed whereas the top base is movable, see Fig. 2. The rheometer prescribes torque of the top adapter around the longitudinal axis and records the resulting rotation. The built-in software then allows for calculating the complex shear modulus $G^{*}(\omega, T)$.

The measurements were performed on several samples for EVA and PVB foil sweeping the temperature domain of $10^{\circ} \mathrm{C}, 20^{\circ} \mathrm{C}, 30^{\circ} \mathrm{C}, 40^{\circ} \mathrm{C}, 50^{\circ} \mathrm{C}, 60^{\circ} \mathrm{C}$ and the frequency domain of $0.001 \mathrm{~Hz}, 0.01 \mathrm{~Hz}, 0.05 \mathrm{~Hz}, 0.1 \mathrm{~Hz}, 0.5 \mathrm{~Hz}, 1 \mathrm{~Hz}, 5 \mathrm{~Hz}, 10 \mathrm{~Hz}, 20 \mathrm{~Hz}, 30 \mathrm{~Hz}, 40 \mathrm{~Hz}$, $50 \mathrm{~Hz}, 100 \mathrm{~Hz}$. Unfortunately, the measured results at frequencies above $50 \mathrm{~Hz}$ exhibited high volatility and were therefore excluded from further analyses. The measured complex moduli were then compared with those provided by eqn (2) together with eqn (3) in the solution of a certain inverse problem. Details can be found in [4] and [5].

As shown in [5] this is a non-linear problem which requires iteration. The Gauss-Newton numerical method with weighting of errors according to their size was employed in this study to minimize the least square difference between measured and calculated complex moduli. This provides the searched values of parameters $G_{\infty},\left\{G_{i}\right\}_{i=1, \ldots, n}, C_{1}, C_{2}$ and consequently the time-sensitive shear modulus $G(t)$ in eqn (1), which in turn enters the numerical analysis discussed in Section 4. For illustration, this modulus is plotted in Fig. 3 for both types of foils.

\section{EXPERIMENTAL TESTING OF FAILURE STRESSES}

The experimental study was performed on laminated glass samples with the nominal plane dimensions of $1100 \times 360 \mathrm{~mm}$ and the thicknesses of glass/polymer/glass layers of 10/0.76/10 mm. Four types of laminated glass samples were tested combining annealed glass 


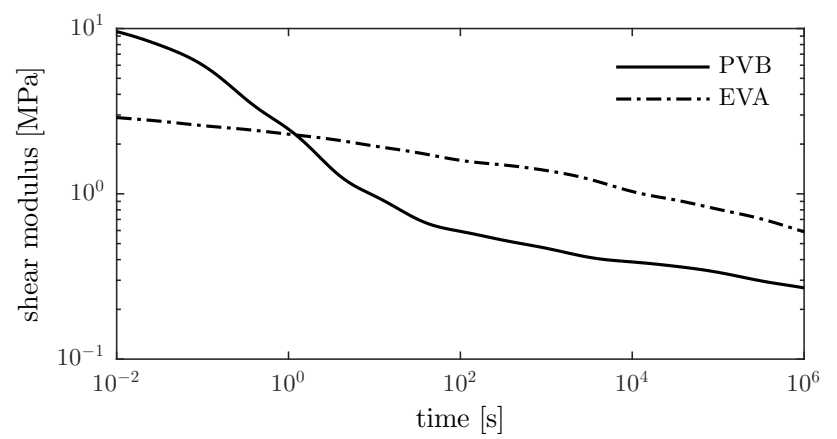

Figure 3: Relaxation modulus of polyvinyl butyral (TROSIFOL ${ }^{\circledR}$ BG R20 by Kuraray) and ethylen-vinyl acetate (EVALAM 80-120 by Pujol) at $25^{\circ} \mathrm{C}$.

(ANG) or heat-strengthen glass (HSG) plies with EVA and PVB foils. Both outer plies were made from the same type of glass.

Two different scenarios were used. Deflection-controlled four-point bending tests were performed on fourteen samples at the Faculty of Civil Engineering at Czech Technical University in Prague. In addition, load-controlled bending tests were carried out on twelve panes loaded under uniformly distributed pressure in vacuum chamber at the science center AdMaS at Brno University of Technology. The measured strains were converted into stresses using the Young modulus of glass, which was obtained from indentation tests performed at the Centre of Excellence Telč. As this quantity is not affected by the thermal tempering process, the measured value of $76.6 \mathrm{GPa}$ was used for both types of glass.

\subsection{Four-point bending}

The experimental setup of the four-point bending test is illustrated in Fig. 4. Eight strain gauges LY 11-10/120 were attached to both glass plies, five on the upper surface in compression and three across the lower surface in tension at the midspan. Laminated glass samples were placed into MTS loading device and central deflections were measured by two displacement sensors. Rubber pads were placed between the supports and loading steel cylinders.

The specimens were loaded in the displacement-controlled mode assuming the loading rate of $1.8 \mathrm{~mm} / \mathrm{min}$. The ambient temperature during the experimental testing was $25^{\circ} \mathrm{C}$. Each specimen was loaded in two steps. The first one led to the fracture of the bottom glass ply. The tensile stresses reported in this paper were evaluated from this stage. Then, the sample was unloaded and reloaded until collapse to obtain its residual load bearing capacity. Because the measured strains from the second stage are affected by a partially fractured bottom glass ply, these data were not used for the tensile strength evaluation.

The failure stresses, set from the extreme measured tensile strains at failure of the bottom glass ply, are reported in Table 1. In this study, we assume that these stresses correspond to the tensile strength of glass in bending for the tested sample. The tensile strengths determined in such a way are within the range of 31-75 MPa for the annealed glass (10 specimens) and within the range of 92-105 MPa for the heat-strengthened glass (4 specimens).

The crack patterns of three samples are shown in Fig. 5 for illustration. Comparing the two patterns and strengths for the samples with annealed glass plies, it is obvious that the area with cracks is more localized for the sample with lower strength, which could be attributed 


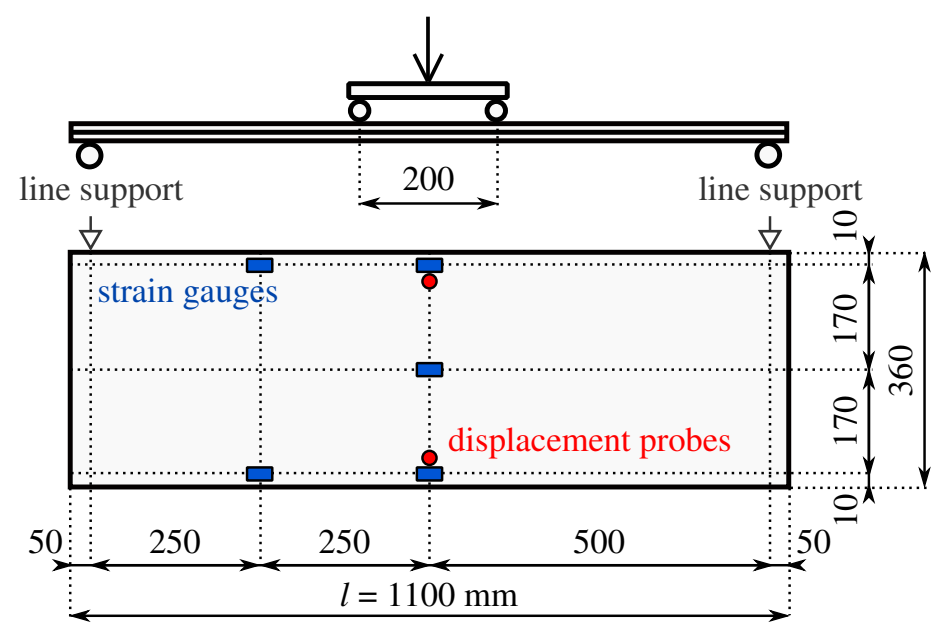

Figure 4: Schema of four-point bending test.

Table 1: Failure stresses for annealed or heat-strengthened glass.

\begin{tabular}{cccccccc}
\hline Glass & Sample & Foil & Stress [MPa] & Glass & Sample & Foil & Stress [MPa] \\
\hline ANG & 1 & EVA & 61 & ANG & 8 & PVB & 75 \\
& 2 & EVA & 66 & & 9 & PVB & 46 \\
& 3 & EVA & 62 & & 10 & PVB & 31 \\
& 4 & EVA & 53 & HSG & 1 & EVA & 101 \\
& 5 & EVA & 35 & & 2 & EVA & 92 \\
& 6 & PVB & 54 & & 3 & PVB & 105 \\
& 7 & PVB & 61 & & 4 & PVB & 103 \\
\hline
\end{tabular}

to a local defect or to an asymmetry in the applied load. For the heat-strengthened glass, the cracks branch and spread across the whole plane area.

\subsection{Uniform bending}

The second complementary experiments correspond to quasi-static bending tests in a vacuum chamber performed following the procedure described in [6]. The samples were placed into the chamber on two linear supports with soft pads made of rubber and loaded by the prescribed uniformed suction at $25^{\circ} \mathrm{C}$, Fig. 6 , resulting in tension in the bottom ply and compression in the top ply.

For all samples, three stain gauges were placed on the upper surface at the midspan. In four cases, three additional strain gauges were placed at the quarter of the span and one at the center of the bottom ply. The loading rate of $0.2-2 \mathrm{kPa} / \mathrm{s}$ was assumed. Because the loading was force-controlled, both glass plies broke at once.

As this set of experiments was not initially proposed for the evaluation of tensile stresses but to study the behavior of laminated glass before and after fracture, the maximum tensile strains were not measured for all samples. The missing values were replaced by the largest values of compressive strains at the midspan, which were always measured. Examining 


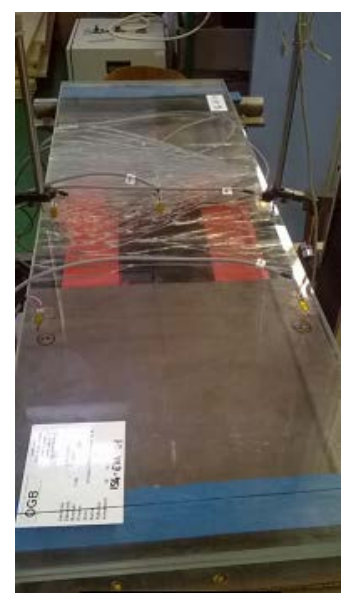

ANG $61 \mathrm{MPa}$

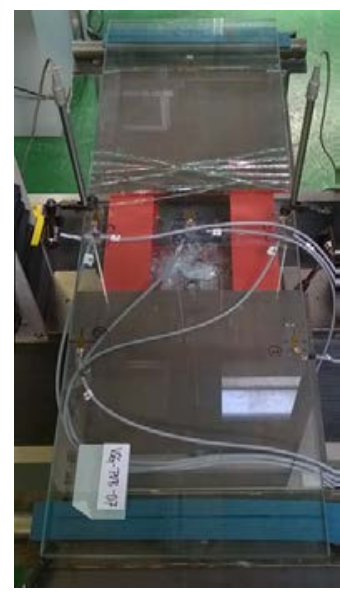

ANG $31 \mathrm{MPa}$

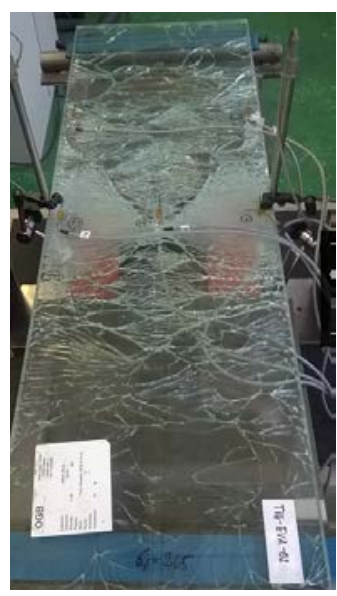

HSG $101 \mathrm{MPa}$

Figure 5: Crack patterns of two samples made of annealed glass (ANG) and one made of heat-strengthened glass (HSG); courtesy of Tomáš Hána from CTU.
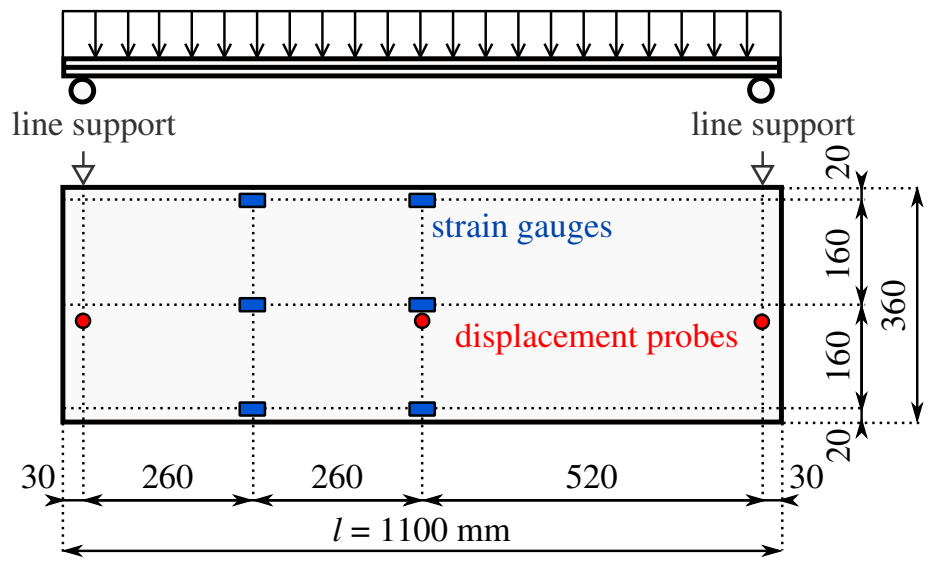

Figure 6: Schema of uniform bending test.

the strain distribution at the cross-section, and because the nominal thicknesses of the two glass plies are the same, allows us to assume that the tensile strains would have the same magnitudes as those in compression on the upper surface of the panel. This is supported by the fact that the deviations of the measured tensile and corresponding compressive strains were less than $5 \%$ for all the four-point bending tests and also for the four samples under uniform pressure with all seven strain gauges.

The stresses at failure corresponding to the tensile stresses of glass are reported in Table 2. The determined tensile strengths are within the range of 35-85 MPa for the annealed glass (6specimens) and within the range of 115-132 MPa for the heat-strengthened glass (6 specimens). Comparing the results in Tables 1 and 2 shows that the ranges of tensile stresses of the annealed glass are similar, whereas for the heat-strengthened glass the strengths 
Table 2: Failure stresses for annealed or heat-strengthened glass.

\begin{tabular}{cccccccc}
\hline Glass & Sample & Foil & Stress [MPa] & Glass & Sample & Foil & Stress [MPa] \\
\hline ANG & 1 & EVA & 85 & HSG & 1 & EVA & 122 \\
& 2 & EVA & 43 & & 2 & EVA & 132 \\
& 3 & EVA & 66 & & 3 & EVA & 115 \\
& 4 & PVB & 69 & & 4 & PVB & 131 \\
& 5 & PVB & 35 & & 5 & PVB & 129 \\
& 6 & PVB & 45 & 6 & PVB & 117 \\
\hline
\end{tabular}

of samples under uniform pressure are higher by about 20-30 MPa. This could be caused by a different level of residual stresses developed during the tempering process.

\section{NUMERICAL ANALYSIS OF FAILURE STRESSES}

The examples introduced in Section 3 were analyzed also numerically. The details about the finite element solver developed for the laminated glass can be found in [7]. It is based on a layer-wise formulation suitable for the modeling of non-linear behavior of laminated glass beams with a viscoelastic interlayer combining the von Kármán model with the assumption of time-independent Poisson ratio. The generalized Maxwell chain model with the parameters from Section 2 is utilized for the time/temperature dependent behavior of the polymer foil.

\subsection{Validation}

The ability of the numerical model to predict the behavior of the laminated glass elements is illustrated in two examples in Fig. 7. The measured deflection and compressive and tensile strains at the center are compared with the numerically predicted equivalent values for a ANG-EVA sample made of annealed glass plies with an ethylene-vinyl acetate foil and for a HSG-PVB sample made of heat-strengthened glass plies with a polyvinyl butyral interlayer. The samples were loaded by a uniform pressure with an increasing intensity, see Fig. 6 . The comparisons in Fig. 7 show an excellent agreement for the ANG-EVA sample with the errors below $2.5 \%$ and still a very good match for the HSG-PVB sample with the error less than $10 \%$ for all quantities. The lines denoted as "lim" correspond to the fully bonded and fully debonded cases within which the results for the three-layer laminate should fall.

\subsection{Four-point bending}

The finite element model was used to set numerically the largest tensile stresses at the critical load. Fourteen samples, corresponding to the scheme from Fig. 4, were analyzed. The predicted failure stresses are summarized in Table 3. They are within the range of 29-73 MPa for the annealed glass and 90-96 MPa for the heat-strengthened glass. These numerical predictions match very well the values from experimental measurements in Table 1; the errors are below $11 \%$, in most cases less than $5 \%$.

\subsection{Uniform bending}

The largest tensile stresses, corresponding to the experimental setup from Fig. 6, are summarized in Table 4 for the twelve samples analyzed. The errors between the experimental data from Table 2 and the numerical predictions is below 12\%, which is a very good 

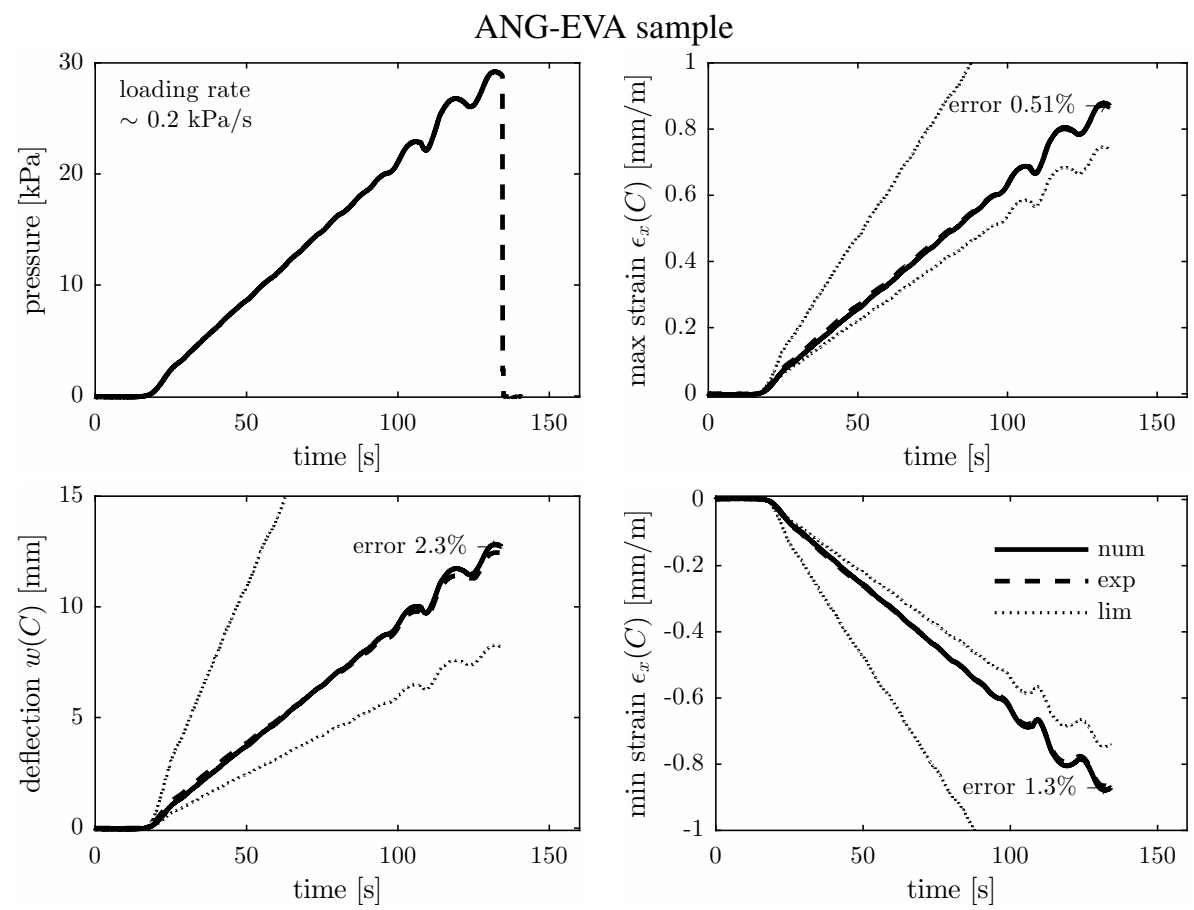

HSG-PVB sample
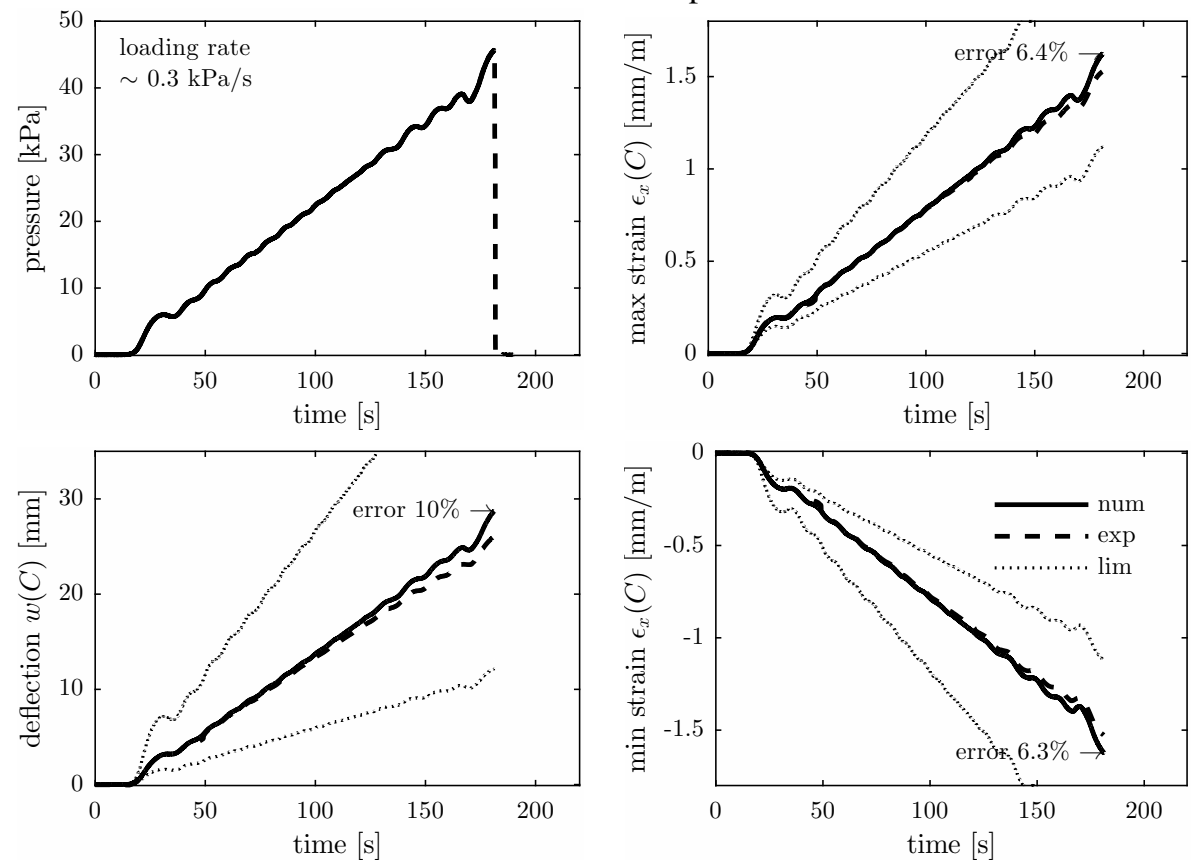

Figure 7: Comparison of experimental data (exp) with numerical predictions (num) complemented with the upper and lower bounds (lim) corresponding to the response of two glass plies bonded fully or at all. 
Table 3: Failure stresses for annealed or heat-strengthened glass.

\begin{tabular}{cccccccc}
\hline Glass & Sample & Foil & Stress [MPa] & Glass & Sample & Foil & Stress [MPa] \\
\hline 1 & ANG & EVA & 60 & ANG & 8 & PVB & 73 \\
2 & & EVA & 65 & & 9 & PVB & 43 \\
3 & & EVA & 61 & & 10 & PVB & 29 \\
4 & & EVA & 51 & HSG & 1 & EVA & 96 \\
5 & & EVA & 35 & & 2 & EVA & 90 \\
6 & & PVB & 50 & & 3 & PVB & 93 \\
7 & & PVB & 55 & & 4 & PVB & 93 \\
\hline
\end{tabular}

Table 4: Failure stresses for annealed or heat-strengthened glass.

\begin{tabular}{cccccccc}
\hline Glass & Sample & Foil & Stress [MPa & Glass & Sample & Foil & Stress [MPa] \\
\hline ANG & 1 & EVA & 78 & HSG & 1 & EVA & 120 \\
& 2 & EVA & 38 & & 2 & EVA & 128 \\
& 3 & EVA & 67 & & 3 & EVA & - \\
& 4 & PVB & 66 & & 4 & PVB & 140 \\
& 5 & PVB & 32 & & 5 & PVB & 133 \\
& 6 & PVB & 46 & 6 & PVB & 124 \\
\hline
\end{tabular}

Table 5: Tensile strength of samples made of annealed or heat-strengthened glass.

\begin{tabular}{ccc}
\hline Value & Strength of ANG [MPa] & Strength of HSG [MPa] \\
\hline Average & 54 & 114 \\
Minimum & 29 & 90 \\
Maximum & 85 & 140 \\
Standard deviation & 15 & 17 \\
\hline
\end{tabular}

agreement considering the fact that the discrepancy of the strains measured at midspan at the center and near the edges is about $5 \%$, in a few cases up to $10 \%$. The numerically determined tensile strengths are within the range of 32-78 MPa for the annealed glass and 120-140 MPa for the heat-strengthened glass. The failure stress of one sample was not determined as the record of the magnitude of the loading pressure was defective.

\section{EVALUATION OF TENSILE STRENGTH}

Both of the above approaches to evaluate the tensile strength of glass can be influenced by various uncertainties arising, for example, from inaccurate fastening of strain gauges or calibration of a measuring device, the selected value of the Young modulus of glass for the determination of stresses, variations in sample dimensions due to manufacturing tolerances, etc. Therefore, we combine the results of both approaches to obtain a larger data set for statistical evaluation. Remember that 32 samples (16 measured, 16 calculated) for the annealed glass and 19 specimens (10 measured, 9 calculated) for the heat-strengthened glass were available.

The extreme values, the average, and the standard deviation of the data sets are summarized in Table 5 for both glass types. Compared with the standard values [8], the 

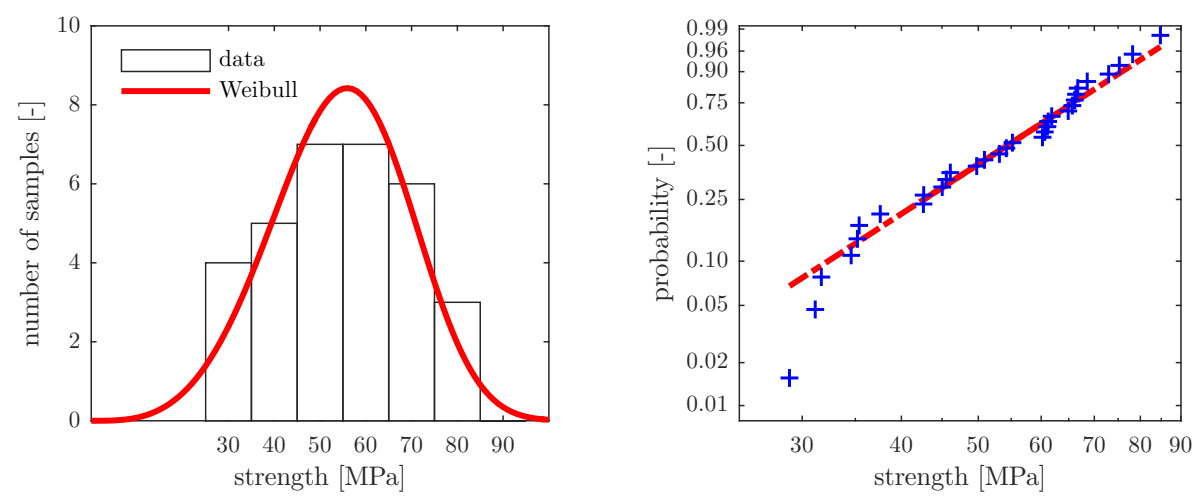

Figure 8: Histogram of tensile strengths of annealed glass complemented with Weibull fit of data (left) and corresponding probability plot (right).
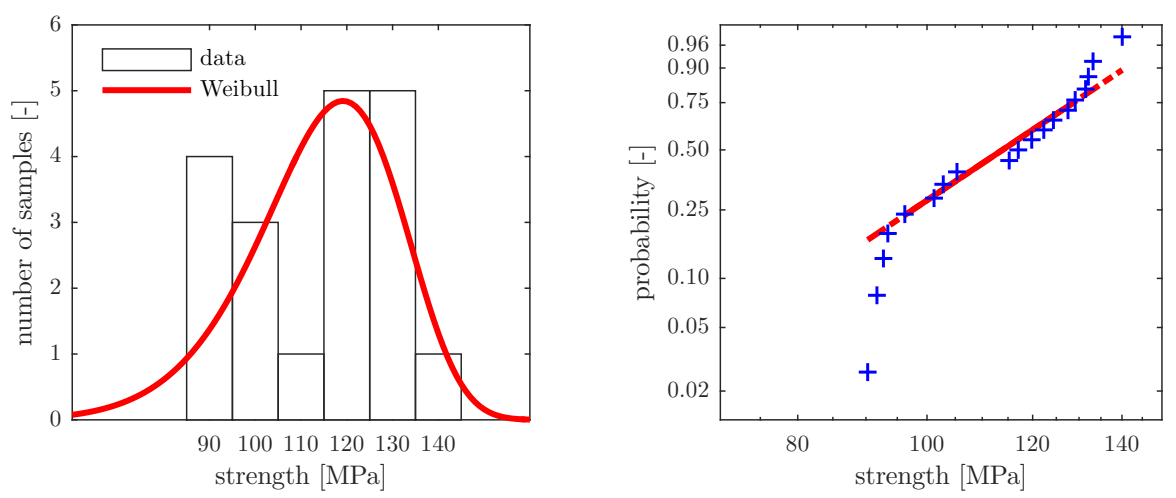

Figure 9: Histogram of tensile strengths of heat-strengthened glass complemented with Weibull fit of data (left) and corresponding probability plot (right).

minimum of the tensile strengths for the annealed glass is under the characteristic value of $45 \mathrm{MPa}$ given by the draft Eurocode, whereas the smallest determined value of the strength of the heat-strengthened glass is about $30 \%$ higher than the value of $70 \mathrm{MPa}$ suggested by the standard.

The occurrence of a given value of tensile strength is shown for the annealed and heatstrengthened glass in Figs 8 and 9. The histogram plots were complemented with twoparameter Weibull fits. The ability of these fits to characterize the data sets is illustrated by the Weibull probability plot. The tensile strength associated with the cumulative probability of $5 \%$ corresponds to $28 \mathrm{MPa}$ for the annealed glass and $72 \mathrm{MPa}$ for the heat-strengthened glass, respectively. The mean values of the Weibull fits rounded to $1 \mathrm{MPa}$ match the average values in Table 5. However, we should still bear in mind a relatively small data sets adopted in this study.

\section{SUMMARY AND CONCLUSIONS}

In this contribution, the tensile strength of the annealed and heat-strengthened glass in laminated glass plates was tested and statistically evaluated. The decisive tensile stresses 
were determined from measured strains and also by numerical analysis performed for given loading scenarios and the measured critical values of loading. The two-parametric Weibull distribution was used to characterize the data sets.

This combined analysis, even though performed on small set of samples, provides us an improved estimates of the tensile strength compared to the typical characteristic values given by prEN 16612. These results will be used for numerical modeling of behavior of the laminated glass samples (produced by the same manufacturer) under low velocity impact.

\section{ACKNOWLEDGMENTS}

This publication was supported by the Czech Science Foundation under project No. 1614770S. We would also like to thank M. Eliášová, T. Hána, Z. Sokol, and V. Hrbek from CTU in Prague, the Centre of Excellence Telc, and the science center AdMaS at TU Brno for performing the experimental measurements reported in this study.

\section{REFERENCES}

[1] Vandebroek, M. \& Belis, J., Fracture strength of glass, engineering testing methods and estimation of characteristic values. COST Action TU0905 Mid-term Conference on Structural Glass, CRC Press, p. 223, 2013.

[2] Haldimann, M., Luible, A. \& Overend, M., Structural Use of Glass, vol. 10, IABSE, pp. 75-76, 2008.

[3] Andreozzi, L., Bati, S.B., Fagone, M., Ranocchiai, G. \& Zulli, F., Dynamic torsion tests to characterize the thermo-viscoelastic properties of polymer interlayer for laminated glass. Construction and Building Materials, 65, pp. 1-13, 2014.

[4] Janda, T., Zemanová, A., Zeman, J. \& Šejnoha, M., Finite element models for laminated glass units with viscoelastic interlayer for dynamic analysis. High Performance and Optimum Design of Structures and Materials II, 166, pp. 245-254, 2016.

[5] Schmidt, J., Janda, T. \& Šejnoha, M., Calibration of model for laminated glass polymer interlayer based on rheometer data. 55th International Scientific Conference Experimental Stress Analysis 2017. Nový Smokovec, 30.05.2017-01.06.2017, Košice: Technical University of Košice, p. 7, 2017.

[6] Melcher, J. \& Karmazínová, M., Experimentální verifikace procesu přetváření a únosnosti plošných dílců s využitím metody zatěžování vakuováním, Z/B - Ověřená technologie. Faculty of Civil Engineering, Brno University of Technology, 2009. RIV/00216305:26110/09:PR24352.

[7] Zemanová, A., Zeman, J. \& Šejnoha, M., Comparison of viscoelastic finite element models for laminated glass beams. International Journal of Mechanical Sciences, 131, pp. 380-395, 2017.

[8] CEN/TC 129, Draft prEN 16612: Glass in building - determination of the load resistance of glass panes by calculation and testing. Technical report, 2013. 